\title{
Surface Oxidation and Subsurface Microstructure Evolution of Alloy 690TT Induced by Partial Slip Fretting Corrosion in High-Temperature Pure Water
}

\author{
Long Xin ${ }^{1} \cdot$ Yongming $\mathrm{Han}^{1} \cdot$ Ligong Ling ${ }^{1,2} \cdot$ Yonghao Lu ${ }^{1} \cdot$ Tetsuo Shoji ${ }^{1,3}$
}

Received: 30 May 2020 / Revised: 28 June 2020 / Accepted: 29 June 2020 / Published online: 26 September 2020

(c) The Chinese Society for Metals (CSM) and Springer-Verlag GmbH Germany, part of Springer Nature 2020

\begin{abstract}
The surface oxidation and subsurface microstructure evolution of Alloy 690TT can occur during partial slip fretting corrosion in high-temperature pure water. Detailed characterization methods such as laser scanning confocal microscopy, scanning electron microscopy, electron probe micro-analyzer, and transmission electron microscopy were used to reveal the related mechanism. The results showed that $\mathrm{Cr}_{2} \mathrm{O}_{3}$ oxides together with a small number of spinel oxides were formed in sticking region since a small quantity of high-temperature water could pass through the gaps between the asperities to oxidize the materials. Widespread distribution of oxides in microslip region consisted of $(\mathrm{Ni}, \mathrm{Fe}) \mathrm{Cr}_{2} \mathrm{O}_{4}$, because $\mathrm{Ni}^{2+}$ and $\mathrm{Fe}^{2+}$ ions could react with $\mathrm{Cr}_{2} \mathrm{O}_{3}$ to generate a small amount of non-stoichiometric spinel oxides. The oxides around micropitting in microslip region consisted of double-layer structure. The outermost layer contained $(\mathrm{Fe}, \mathrm{Cr}$ )-rich oxides due to the effect of fretting leading to mechanical mixing between $\mathrm{Cr}_{2} \mathrm{O}_{3}$ and $(\mathrm{Ni}, \mathrm{Fe})(\mathrm{Fe}, \mathrm{Cr})_{2} \mathrm{O}_{4}$. The inner layer consisted of (Fe, Ni)-rich oxides owing to the consumption of $\mathrm{Cr}_{2} \mathrm{O}_{3}$ by the reaction with $\mathrm{Ni}^{2+}$ and $\mathrm{Fe}^{2+}$ ions. The reciprocating motion of oxide particles in microslip region resulted in the stress-strain supporting the recrystallization for the formation and development of a tribologically transformed structure in subsurface and plowing effect by fretting in surface.
\end{abstract}

Keywords Fretting corrosion · Oxidation · Partial slip · Alloy 690TT · Microstructure $\cdot$ High-temperature water

\section{Introduction}

Alloy 690TT (thermally treated) is a nickel-based superalloy, which has been widely used as a structural material for the heat transfer tube in a steam generator (SG) in pressurized water reactor (PWR) nuclear power plant due to its better resistance to stress corrosion and intergranular corrosion $[1,2]$.

Fretting corrosion is a type of fretting damage in which chemical reaction predominates between the constituents of

Available online at http://link.springer.com/journal/40195.

Yonghao $\mathrm{Lu}$

lu_yonghao@mater.ustb.edu.cn

1 National Center for Materials Service Safety, University of Science and Technology Beijing, Beijing 100083, China

2 Nuclear and Radiation Safety Center, Beijing 102401, China

3 Frontier Research Initiative, New Industry Creation Hatchery Center, Tohoku University, 6-6-10, Aramaki Aoba, Aoba-ku, Sendai 980-8579, Japan contacting surface and environment [3]. Fretting corrosion is one of main failure modes in SG, mainly occurring in a limited position between the heat transfer tube and its support frame in high-temperature and high-pressure (HTHP) water [4-6]. At this stage, the research on fretting corrosion in simulated secondary side HTHP water has become mainstream, which can provide reference for the safe operation of heat transfer tubes under real working condition.

The oxidation of contacting surfaces is a fundamental process during fretting corrosion in HTHP water [7]. The morphology, size and crystal structure of oxides are highly related to the wear and corrosion performance of a material. For example, $\mathrm{Cr}_{2} \mathrm{O}_{3}$-rich tribolayer had a better wear resistance than that of $\mathrm{NiCr}_{2} \mathrm{O}_{4}$-rich tribolayer, because the former was stable with fewer occurrence of cracking [8]. As the thickness of oxide film increased, the wear resistance also increased due to the prevention from metal-to-metal contact and material transfer [9]. If oxidized wear debris became compacted onto the contacting surfaces, it would show better wear and corrosion protection [10, 11]. The research by Ming et al. [12] found that there were five stages of change in friction coefficient 
during fretting wear in HTHP water, which was likely relevant to the evolution of oxides. The work by Guo et al. [13] revealed that the oxides could also cause abrasive wear when the displacement amplitude was low in HTHP water. Lai et al. [14] found that the cracking occurred within oxides in HTHP water. The research by Xin et al. [15] revealed that the crushed oxides accelerated the formation of wear debris. Additionally, the oxides could result in pitting-like damage during fretting corrosion in HTHP water [16]. Under high normal load or low displacement amplitude, fretting ran in partial slip regime (PSR) [11, 16-18]. The oxides within microslip region and sticking region would be different. It can be seen from above researches that the fretting corrosion process is very complicated. The evolution of oxides during fretting corrosion in HTHP water is still not clear.

The detachment of wear particles resulting in the material loss is one of the main failure modes during fretting. At the early stage of degradation process, a special layer from which particles detach is always produced through plastic deformation. This layer is called tribologically transformed structure (TTS) [19], which is different from the bulk material. TTS layer consists of nanograins along with high hardness, which can act as a bearing layer to reduce wear. However, the corresponding high brittleness may accelerate cracking [20]. Additionally, high density of grain boundary within TTS layer may expedite oxidation during fretting corrosion. TTS can be formed in gross slip regime (GSR) easily and quickly [21, 22]. However, few researches $[11,22]$ on TTS in partial slip regime (PSR) is found. The formation and development of TTS in PSR has not been fully understood especially in HTHP water.

Therefore, main research objective of this study is to evaluate the surface oxidation and subsurface microstructure evolution of Alloy 690TT during fretting corrosion in HTHP water within PSR.

\section{Materials and methods}

\subsection{Materials}

The flat specimens of Alloy 690TT with the dimensions of $25 \mathrm{~mm} \times 20 \mathrm{~mm} \times 2 \mathrm{~mm}$ were mechanically polished to a surface roughness (Ra) of $0.4 \mu \mathrm{m}$. Type 304 stainless steel (SS) balls with a diameter of $10 \mathrm{~mm}$ and a surface roughness (Ra) of $0.5 \mu \mathrm{m}$ were used for fretting tests. Table 1 lists the chemical composition of test materials.

\subsection{Experiments}

Fretting tests in HTHP pure water were carried out using an oscillating test rig with a ball-on-plate configuration, as shown in Fig. 1. The test machine mainly consists of two parts. One is the water loop system which was applied to control water chemistry in an autoclave, as shown in Fig. 1a. High purity water was used as the test solution in autoclave under high temperature of $288^{\circ} \mathrm{C}$ and high pressure of 8.3 MPa. Dissolved oxygen (DO) was controlled by continuous bubbling with pure nitrogen gas $(99.999 \%)$ and monitored online in real time. In this study, the DO concentration of $2 \mathrm{ppm}$ and $\mathrm{pH}$ value of 5.6 were selected. As shown in Fig. 1b, the other is the fretting assembly, which was set into the autoclave. The normal force was applied by a stepping motor which was well controlled (within $\pm 1 \mathrm{~N}$ ) by a numerical control system. The resolution of relative displacement is within $\pm 5 \mu \mathrm{m}$. The normal load, displacement amplitude, frequency, duration time applied in all the tests were $100 \mathrm{~N}$, $60 \mu \mathrm{m}, 30 \mathrm{~Hz}$ and $2 \mathrm{~h}$, respectively. Table 2 shows the test condition and water chemistry parameter.

\subsection{Analysis Techniques}

Worn surface was observed via laser scanning confocal microscopy (LSCM, Olympus LEXT OLS4000) and scanning electron microscopy (SEM, Zeiss Auriga). The wear volume and cross-sectional profile of Alloy 690TT were also measured via LSCM. The alloying elements were analyzed by an energy-dispersive spectrometer (EDS) in SEM and electron probe micro-analyzer (EPMA, JEOL JXA8230). The oxide type on worn surface was determined by microRaman spectroscopy (LabRAM HR Evolution). The crosssectional foil of worn surface was prepared by focused ion beam (FIB) technique (FEI, Helios Nanolab 600i) along the depth direction. Then the thin foil was observed via transmission electron microscopy (TEM, FEI Tecnai $G^{2}$ F20) equipped with an EDX detector operating at $200 \mathrm{kV}$. The imaging of bright field (BF), dark field (DF), selected area electron diffraction (SAED), high-resolution transmission electron microscopy (HRTEM) and high-angle annular dark field (HAADF) in scanning transmission electron microscope (STEM) mode was done to reveal the microstructure evolution.
Table 1 Chemical compositions of alloys (wt \%)

\begin{tabular}{llllllllll}
\hline Specimen & $\mathrm{Ni}$ & $\mathrm{Fe}$ & $\mathrm{Cr}$ & $\mathrm{C}$ & $\mathrm{Ti}$ & $\mathrm{Mn}$ & $\mathrm{Si}$ & $\mathrm{P}$ & $\mathrm{S}$ \\
\hline Alloy 690TT & $\mathrm{Bal}$. & 11.6 & 29.9 & 0.025 & 0.33 & 0.25 & 0.33 & 0.086 & 0.0025 \\
Type 304SS & 9.35 & $\mathrm{Bal}$. & 18.3 & 0.018 & - & 1.31 & 0.31 & 0.034 & 0.0025 \\
\hline
\end{tabular}




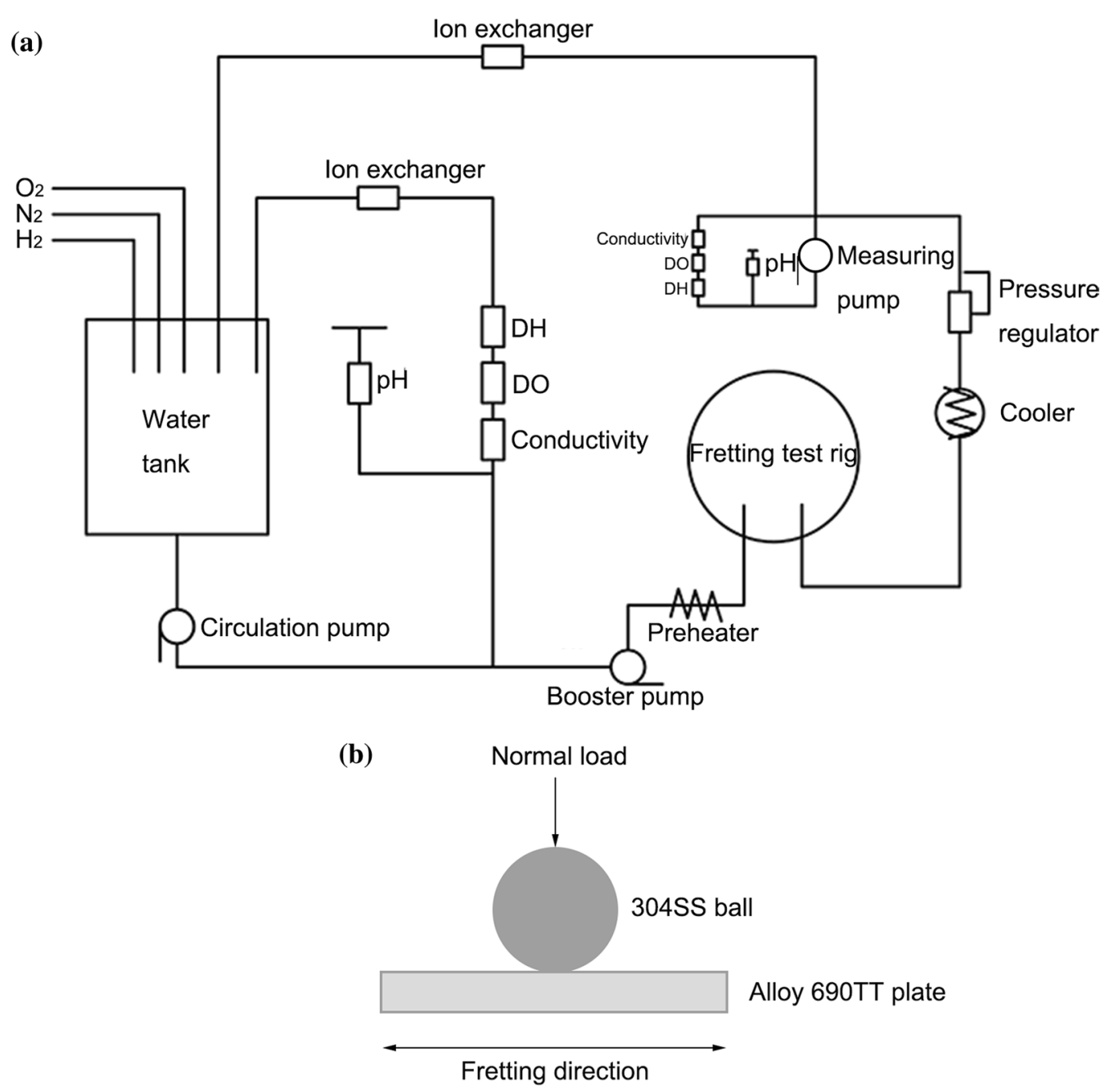

Fig. 1 Schematic diagram of a the water loop, $\mathbf{b}$ the configuration of fretting test rig

Table 2 Fretting test conditions and water chemistry parameters

\begin{tabular}{llllllll}
\hline Normal load & Displacement amplitude & Frequency & Duration time & Temperature & Pressure & PH & DO \\
\hline $100 \mathrm{~N}$ & $60 \mu \mathrm{m}$ & $30 \mathrm{~Hz}$ & $2 \mathrm{~h}$ & $288{ }^{\circ} \mathrm{C}$ & $8.3 \mathrm{MPa}$ & 5.6 & $2 \mathrm{ppm}(\mathrm{by} \mathrm{weight})$ \\
\hline
\end{tabular}

\section{Results}

Figure 2a shows the LSCM morphology of worn surface in Alloy 690TT after fretting corrosion in HTHP water. The appearance of wear scar shows partial slip feature including central sticking region and ring-shaped microslip region at the edges. Figure $2 b$ shows the cross-sectional profile of wear scar, which is taken from the dash line in Fig. 2a. The value of measured wear volume and depth are also inserted in the figure. It can be found that the profile of wear surface of Alloy 690TT is jagged. The measured maximum wear depth is approximately $11.5 \mu \mathrm{m}$ with the value of wear volume of $7.42 \times 10^{5} \mu \mathrm{m}^{3}$. Figure $2 \mathrm{c}$ shows the EPMA-line scanning analysis for oxygen concentration on worn surface. It can be found that the oxygen content is mainly concentrated in microslip region, which is also a typical feature of partial slip fretting corrosion [11, 12, 18]. The surfaces of central sticking region and unworn region also show signs of oxidation, but to a much lesser extent than the microslip region.

Figure 3a shows magnified SEM morphology of central sticking region of wear scar on Alloy 690TT. It can be observed that there are a large number of tiny and individual oxide particles. Some single oxides come together to form oxide clusters. The outer surface of oxides is smooth 

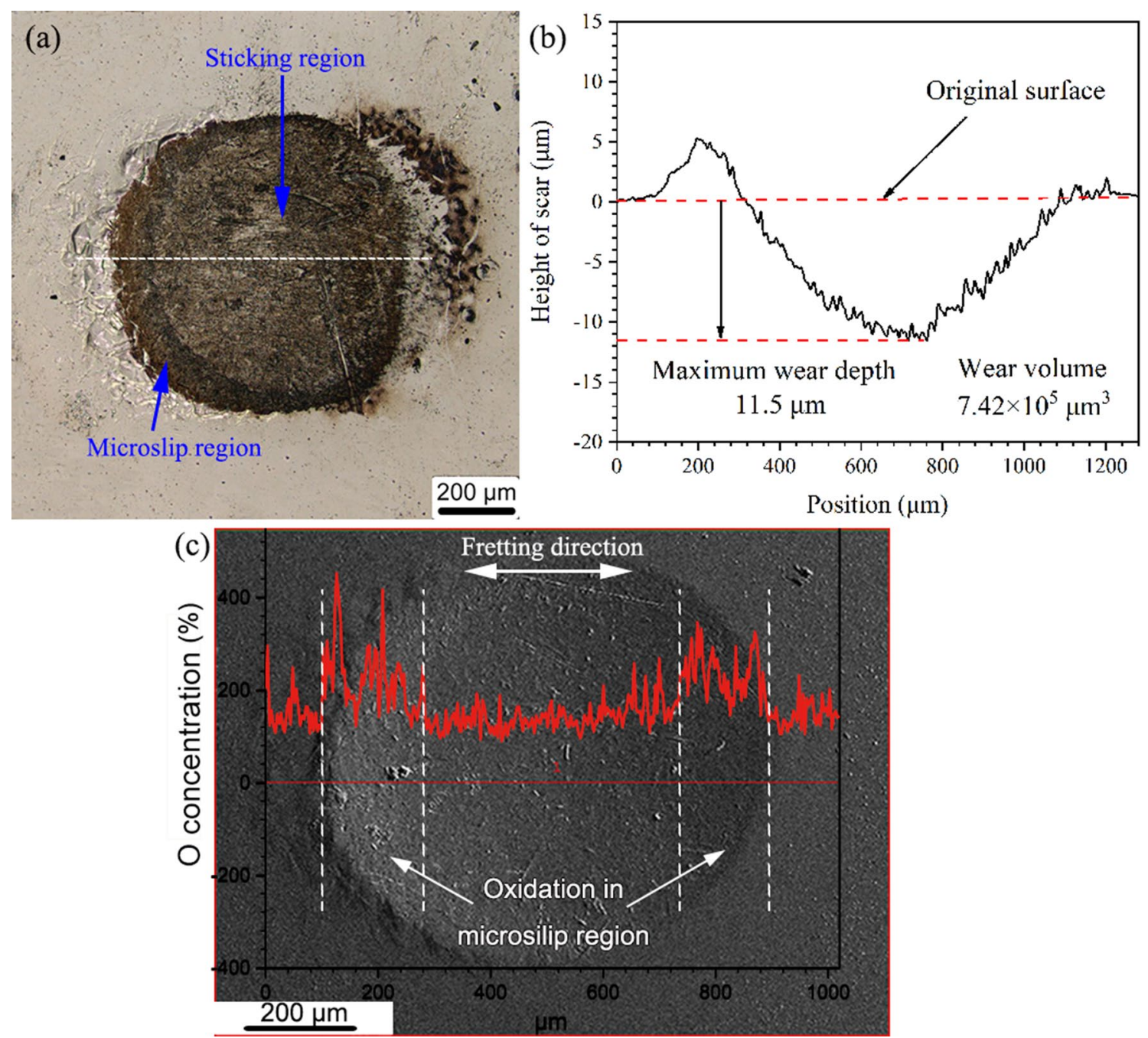

Fig. 2 a LSCM morphology of wear scar on Alloy 690TT after fretting corrosion in HTHP water, $\mathbf{b}$ cross-sectional profile of the wear scar with the value of measured wear volume, $\mathbf{c}$ EPMA-line scanning analysis for the oxygen concentration on worn surface
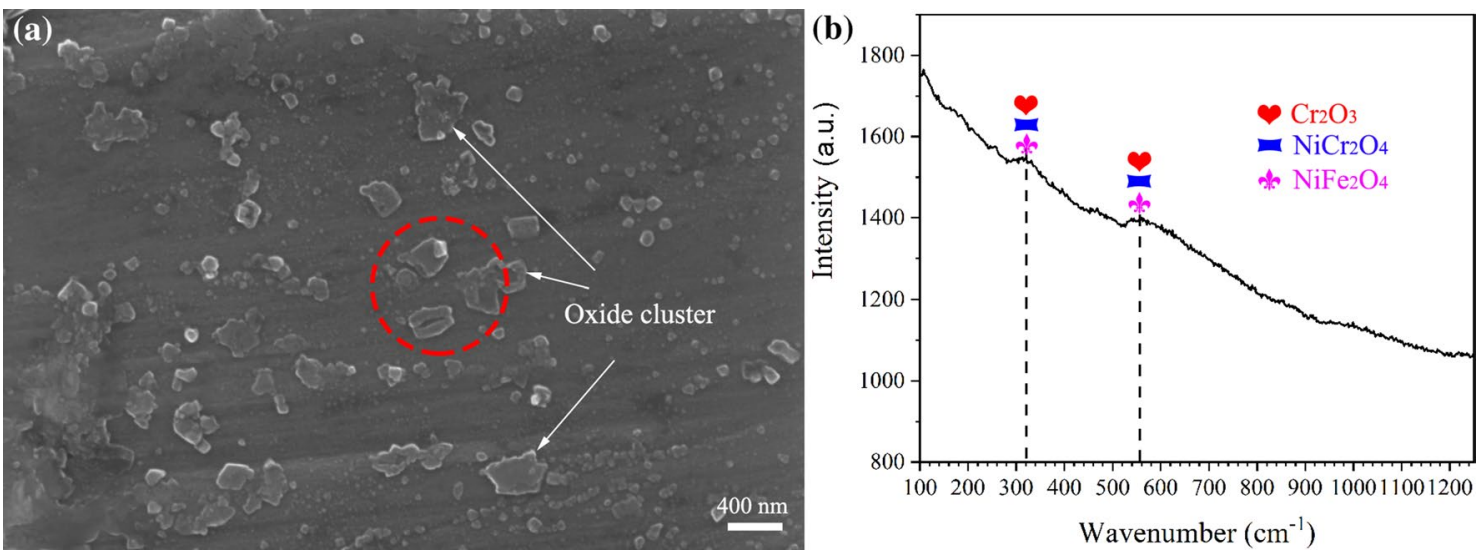

Fig. 3 a Magnified SEM morphology of central sticking region of wear scar on Alloy 690TT and $\mathbf{b}$ corresponding Raman analysis of the oxide film in the red circle in a 
and has no edges and corners. Figure $3 \mathrm{~b}$ shows the corresponding Raman analysis of oxide film in the red circle in Fig. 3a. It can be clearly seen that the peak intensity is weak, which indicates that the oxide film is very thin. Two peaks at 316 and $558 \mathrm{~cm}^{-1}$ indicate the presence of $\mathrm{Cr}_{2} \mathrm{O}_{3}$,
$\mathrm{NiCr}_{2} \mathrm{O}_{4}$ and $\mathrm{NiFe}_{2} \mathrm{O}_{4}$, as shown in Table 3 which summarizes the wavenumber corresponding to the typical oxides for $\mathrm{Ni}-\mathrm{Fe}-\mathrm{Cr}$ alloys in Raman spectra. The main peak at $558 \mathrm{~cm}^{-1}$ and the secondary peak at $316 \mathrm{~cm}^{-1}$ indicate

Table 3 Wavenumber corresponding to the typical oxides for Ni-Fe-Cr alloys in Raman spectra

\begin{tabular}{lllllll}
\hline Oxides & Kim et al. [23] & Kim et al. [24] & $\begin{array}{l}\text { Maslar et al. } \\
{[25-27]}\end{array}$ & Wang et al. [28] & Xiao et al. [29] & $\begin{array}{l}\text { Miyazawa } \\
\text { et al. [30] }\end{array}$ \\
\hline
\end{tabular}

\begin{tabular}{|c|c|c|c|c|}
\hline \multirow[t]{4}{*}{$\mathrm{NiO}$} & & 1074 & & \\
\hline & & 910 & & \\
\hline & & 725 & & \\
\hline & $\underline{480}$ & $\underline{532}$ & $\underline{490}$ & \\
\hline \multirow[t]{5}{*}{$\mathrm{Cr}_{2} \mathrm{O}_{3}$} & 608 & 610 & 613 & \\
\hline & $\underline{\mathbf{5 5 0}}$ & $\underline{550}$ & $\underline{552}$ & \\
\hline & & 528 & 527 & \\
\hline & 347 & 352 & 350 & \\
\hline & 302 & 302 & 300 & \\
\hline \multirow[t]{7}{*}{$\mathrm{NiFe}_{2} \mathrm{O}_{4}$} & $\underline{695}$ & $\underline{702}$ & $\underline{705}$ & \\
\hline & 650 & 654 & $\underline{655}$ & \\
\hline & & 595 & 592 & \\
\hline & 565 & 574 & 570 & \\
\hline & 488 & 492 & 488 & \\
\hline & 455 & 460 & 457 & \\
\hline & 325 & & & \\
\hline \multirow[t]{7}{*}{$\mathrm{NiCr}_{2} \mathrm{O}_{4}$} & & & & 796 \\
\hline & 665 & 687 & $\underline{686}$ & $\underline{686}$ \\
\hline & & & & 580 \\
\hline & 549 & $550-560$ & & \\
\hline & $\underline{508}$ & $\underline{513}$ & $\underline{512}$ & 511 \\
\hline & 425 & 429 & & 425 \\
\hline & 325 & & & \\
\hline
\end{tabular}

$\mathrm{FeCr}_{2} \mathrm{O}_{4}$

181

\begin{tabular}{|c|c|c|c|c|}
\hline & & & 590 & 600 \\
\hline & & & 492 & \\
\hline $\mathrm{Fe}_{3} \mathrm{O}_{4}$ & 665 & 661 & & \\
\hline & 524 & 532 & & \\
\hline & 292 & 300 & & \\
\hline $\mathrm{Fe}_{2} \mathrm{O}_{3}$ & $\underline{1310}$ & $\underline{1320}$ & & \\
\hline & 1100 & & & \\
\hline & 1055 & & & \\
\hline & 813 & & & \\
\hline & 655 & & & \\
\hline & 607 & 613 & & \\
\hline & 494 & 498 & & \\
\hline & 406 & 412 & & \\
\hline & $\underline{290}$ & $\underline{293}$ & & \\
\hline & 243 & 247 & & \\
\hline & 224 & 225 & & \\
\hline
\end{tabular}


that $\mathrm{Cr}_{2} \mathrm{O}_{3}$ is the major oxide with higher amount and the amount of $\mathrm{NiCr}_{2} \mathrm{O}_{4}$ and $\mathrm{NiFe}_{2} \mathrm{O}_{4}$ is lower.

Figure 4a shows a typical SEM morphology of microslip region of wear scar on Alloy 690TT. It can be seen that there are three rows of continuous pitting-like damage. The formation and development of the pitting has been proved to be due to the press-in by the motion of oxide particle [16]. Figure $4 \mathrm{~b}$ shows magnified SEM morphology taken from the rectangle in Fig. 4a. The oxides around the micropitting can also be found. The slip bands induced by the motion of oxide particles appear inside the micropitting. Figure $4 \mathrm{c}$ shows another typical SEM morphology of the microslip region of wear scar on Alloy 690TT. There are two kinds of oxides on worn surface. One is general oxide which is densely distributed. The other is large oxide particle which is sparsely distributed and pressed into the surface.

Figure 5 shows the EDX analysis results for the two oxide particles in Fig. 4c. For particle 1, the elements of $\mathrm{O}$ and $\mathrm{Fe}$ are highly rich with small amount of $\mathrm{Ni}, \mathrm{Cr}$ and $\mathrm{Al}$. For particle 2, the content of $\mathrm{O}$ and $\mathrm{Fe}$ is higher than that in particle 1. However, less content of $\mathrm{Ni}$ and $\mathrm{Cr}$ is observed.
General oxides formed in microslip region of Alloy 690TT were analyzed by Raman spectroscopy. Figure 6a shows the worn surface with five locations for Raman test. Due to higher oxygen concentration, the microslip region is obviously darker than central sticking region. Figure $6 \mathrm{~b}$ shows the indexed Raman analyses taken from the five points in Fig. 6a. Raman spectra are almost identical among the five tests. The wavenumber of Raman is compared to Table 3 to identify the phase of oxides. The major oxides existing on worn surface can be revealed by the highest peak. $\mathrm{NiCr}_{2} \mathrm{O}_{4}$ and $\mathrm{FeCr}_{2} \mathrm{O}_{4}$ are the dominant oxides at a wavenumber of $682.1 \mathrm{~cm}^{-1}$ with a weak one at $325.7 \mathrm{~cm}^{-1}$.

Figure 7 a shows the SEM image of microslip region which is similar to Fig. 4a. The location indicated by dashed box is the selected site for FIB technique, in which the micropitting and the oxides around micropitting are included. Figure $7 \mathrm{~b}$ shows the SEM image of the selected site on which a platinum layer is deposited to prevent from beam damage. Figure 7c shows the bright field transmission electron microscopy (BFTEM) image of the cross section. It is obviously observed that the pressing mark induced by the oxide particle exists. The carbides also can be seen along
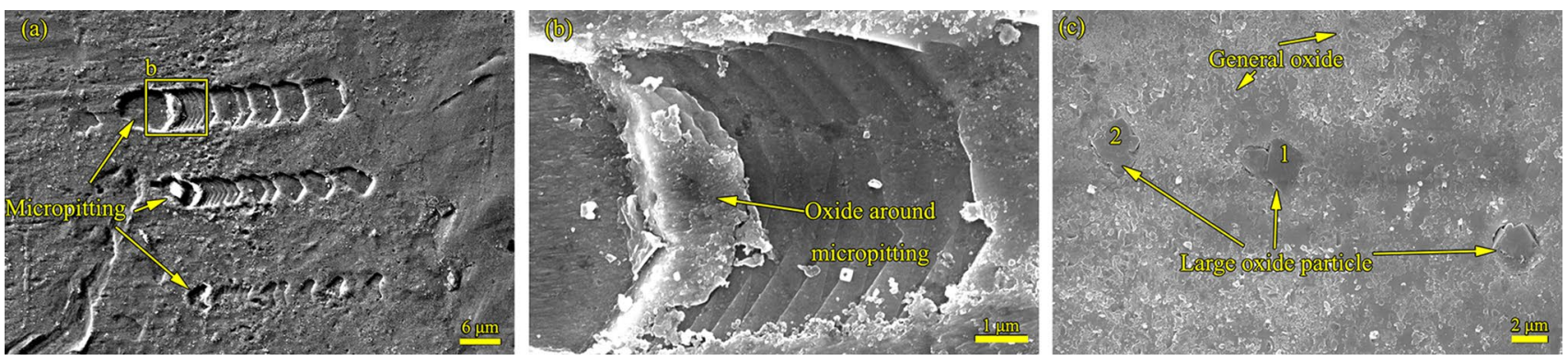

Fig. 4 a Typical SEM-SE2 morphology of microslip region of wear scar in Alloy 690TT, (b) magnified SEM-InLence morphology taken from the rectangle in a, $\mathbf{c}$ typical SEM-InLence morphology showing the oxide distribution
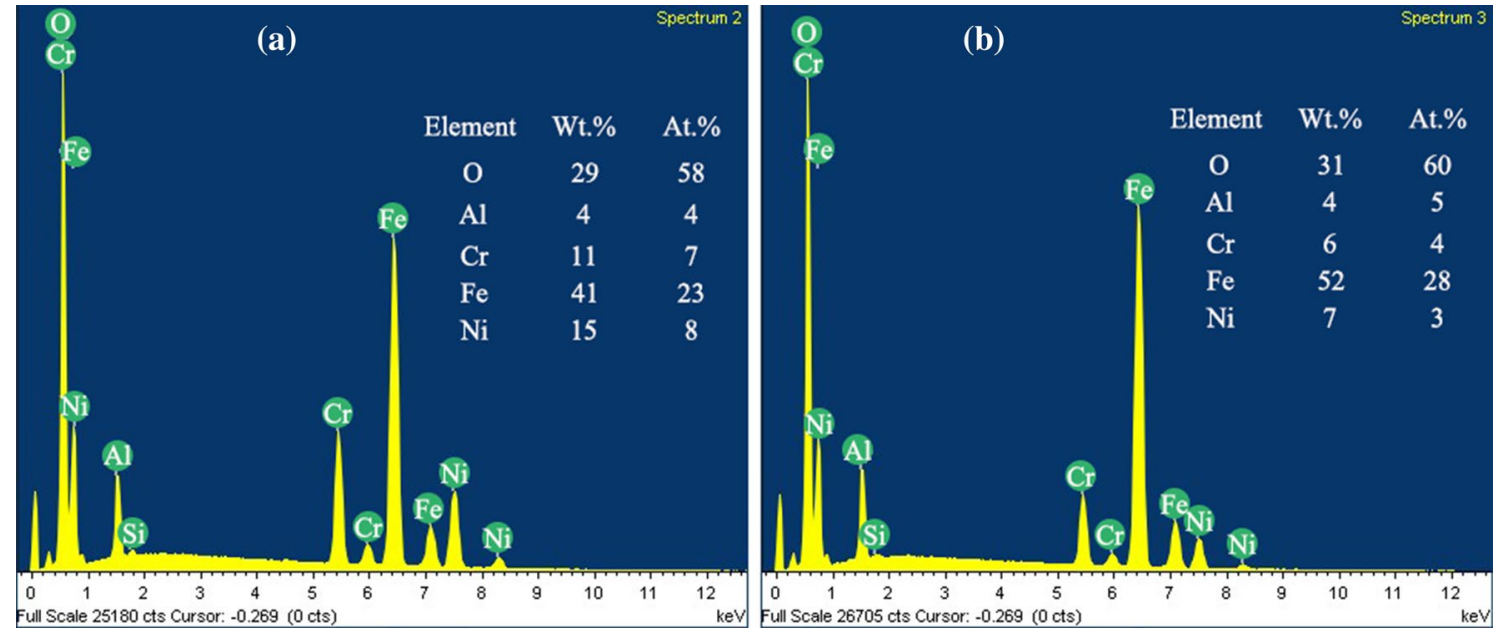

Fig. 5 EDS point analysis results for the oxide particle $\mathbf{a} 1$ and $\mathbf{b} 2$ in Fig. $4 \mathrm{c}$ 

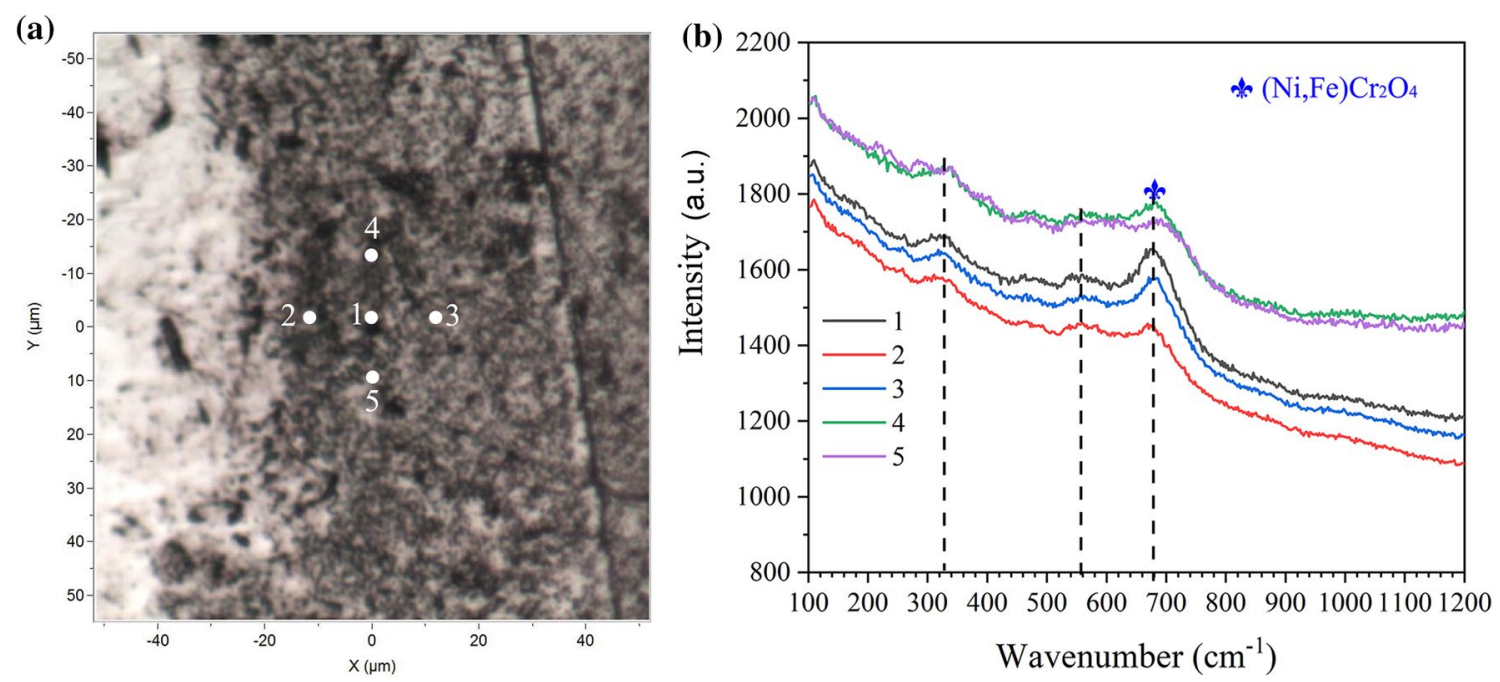

Fig. 6 Raman analysis for the selected worn surface of Alloy 690TT after fretting corrosion in HTHP water: a LSCM image showing five locations for Raman test, $\mathbf{b}$ indexed Raman spectra of these five tests
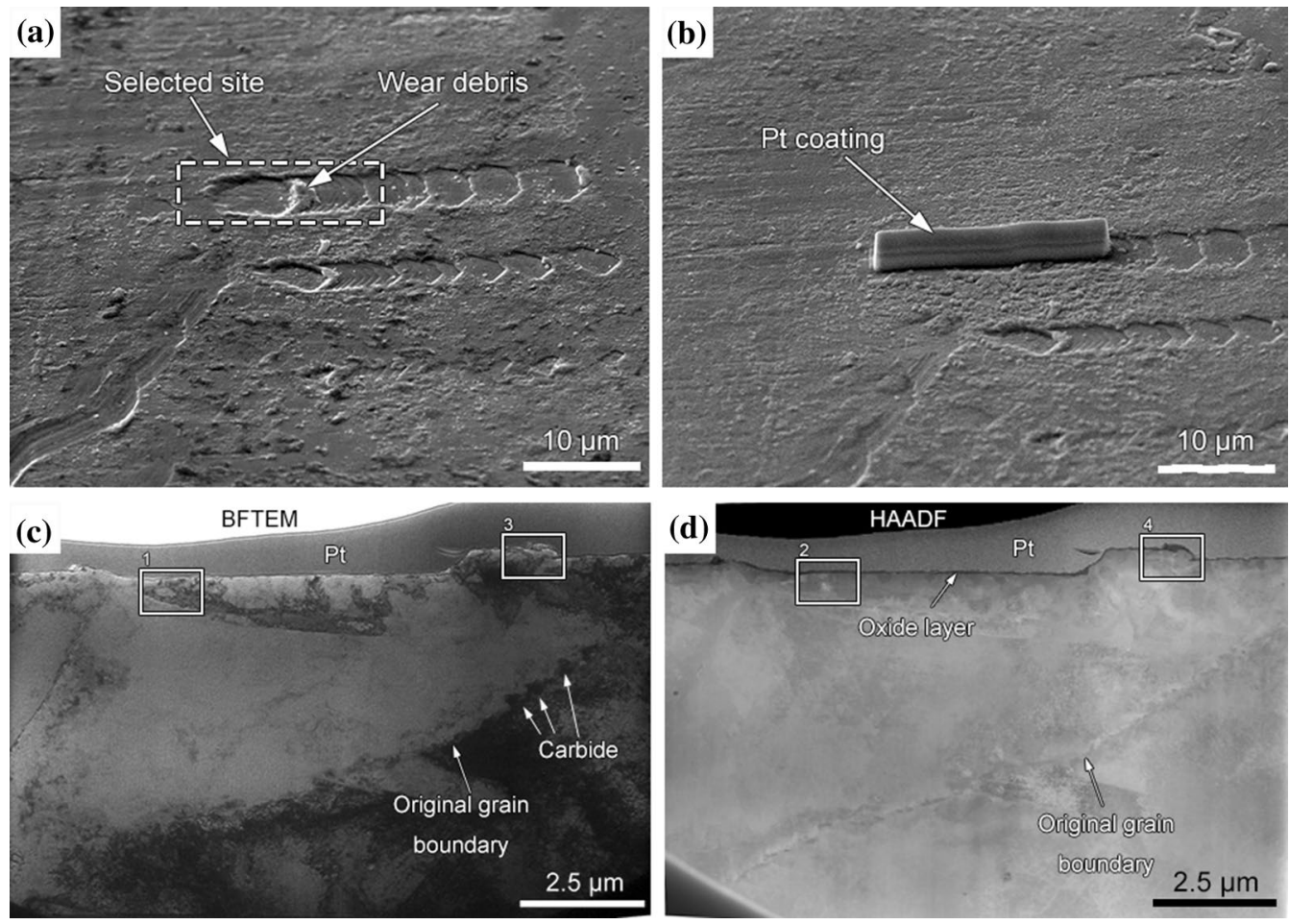

Fig. 7 SEM images of microslip region on Alloy 690TT after fretting corrosion in HTHP water showing a the area chosen for extraction by FIB lift-out and $\mathbf{b}$ the deposited Pt coating on the selected site. TEM results for $\mathbf{c}$ BFTEM image of the cross section extracted using a FIB, $\mathbf{d}$ corresponding STEM-HAADF image

with original grain boundary. Figure $7 \mathrm{~d}$ shows the corresponding STEM-HAADF image of the cross section. Under HAADF imaging, bright and dark regions, respectively, represent heavy and light elemental concentration. A thin oxide layer just below the Pt layer with a thickness of 50-200 nm can be found at the outermost in the cross section.
Figure 8a shows the BFTEM image obtained from the rectangle 1 in Fig. 7c with the inserted SAED. It can be found that there are several refined grains (red-colored areas) near the wear surface with random orientations. The corresponding SAED indicates the coexistence of both grains and subgrains with the dominating phase of Ni-matrix. Figure $8 \mathrm{~b}$ 

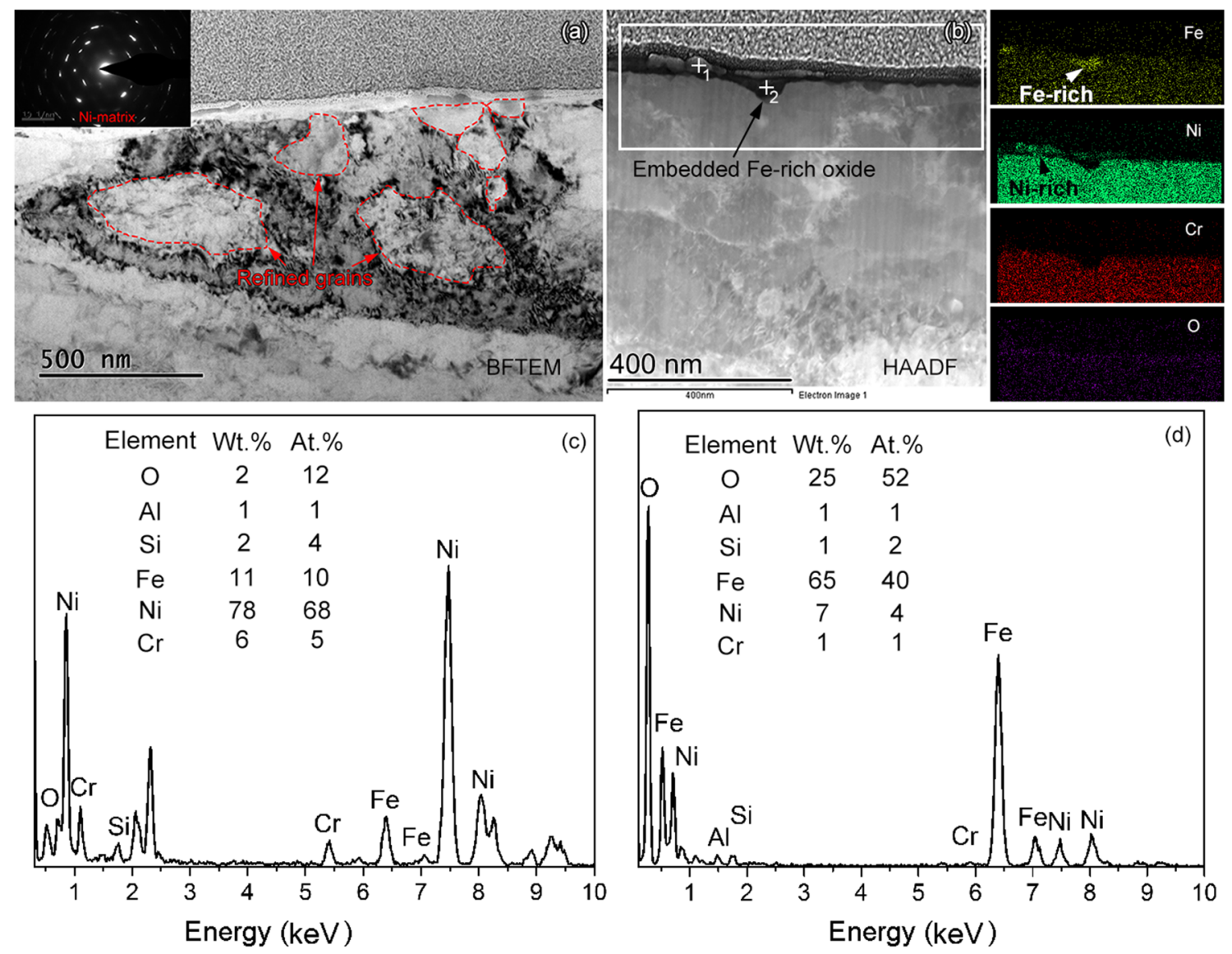

Fig. 8 a BFTEM image obtained from the rectangle 1 marked in Fig. 7c with the inserted SAED, b STEM-HAADF image of the rectangle region 2 in Fig. 7d and the corresponding EDS elemental mapping of $\mathrm{Fe}, \mathrm{Ni}, \mathrm{Cr}$ and $\mathrm{O}$ and quantified EDS results on $\mathbf{c}$ point 1 and $\mathbf{d}$ point 2 marked in b

shows the corresponding STEM-HAADF obtained from the rectangle 2 in Fig. $7 \mathrm{~d}$ and the corresponding EDX elemental maps of $\mathrm{Fe}, \mathrm{Ni}, \mathrm{Cr}$ and $\mathrm{O}$. There is a Ni-rich layer on the top. Further quantified EDX analysis of point 1 marked in Fig. 8b indicates that the Ni-rich layer contains a small amount of $\mathrm{O}, \mathrm{Al}, \mathrm{Si}$ and $\mathrm{Cr}$ with some concentration of $\mathrm{Fe}$, as shown in Fig. 8c. Just below Ni-rich layer, there is a Fe-rich oxide particle embedding in the pit. This oxide particle contains large amount of $\mathrm{Fe}$ and $\mathrm{O}$ and a few Ni with little $\mathrm{Cr}, \mathrm{Al}$ and $\mathrm{Si}$, indicated by the EDX analysis in Fig. 8d.

Figure 9a shows the BFTEM image obtained from the rectangle 3 marked in Fig. 7c. It can be found that the oxides around the micropitting contains a large oxide particle and ultra-fine-grained nanograins which can be regarded as the wear debris. Just below the oxides, there is an unoxidized grain which is always called tribologically transformed structure (TTS). Figure 9b shows the indexed SAED taken from the dash circle 1 in Fig. 9a. It can be found that this region contains the austenite derived from the bulk material. Figure 9c shows the indexed SAED pattern taken from the location 2 in Fig. 9a. The oxides around the micropitting may include the spinel and $(\mathrm{Fe}, \mathrm{Cr})_{2} \mathrm{O}_{3}$, while the austenite phase exists in TTS and bulk material. Figure 9d, e shows the corresponding dark field transmission electron microscopy (DFTEM) images obtained from different diffraction spots in Fig. 9c. It clearly observed the grain distribution of the surface oxides, TTS and bulk material. Figure 9f shows the distribution of grain size in oxide layer. The range of grain size is within $5-65 \mathrm{~nm}$. The average grain size is approximately $17 \mathrm{~nm}$ by calculation.

Figure 10a-f shows the STEM-HAADF image of the rectangle 4 marked in Fig. 7d and the corresponding EDX elemental maps of $\mathrm{Fe}, \mathrm{Ni}, \mathrm{Pt}, \mathrm{Cr}$ and $\mathrm{O}$. The oxides around the micropitting contain the enrichment of $\mathrm{Fe}, \mathrm{Cr}$, and $\mathrm{O}$ as well as the local concentration of Ni. Figure $10 \mathrm{~g}$ shows the line scan analyses by EDX conducted on the cross section of the sample across the oxide layer. A distinct boundary appears between the two layers of the oxide: $\mathrm{Fe}$ and $\mathrm{Cr}$ are accumulated in the outer layer; $\mathrm{Fe}$ and $\mathrm{Ni}$ are detected in the inner layer. Just below the inner layer, there exists the concentration of $\mathrm{Ni}$ and $\mathrm{Cr}$. Meanwhile, $\mathrm{Ni}$ and $\mathrm{Cr}$-deficient regions are observed under the concentration. 


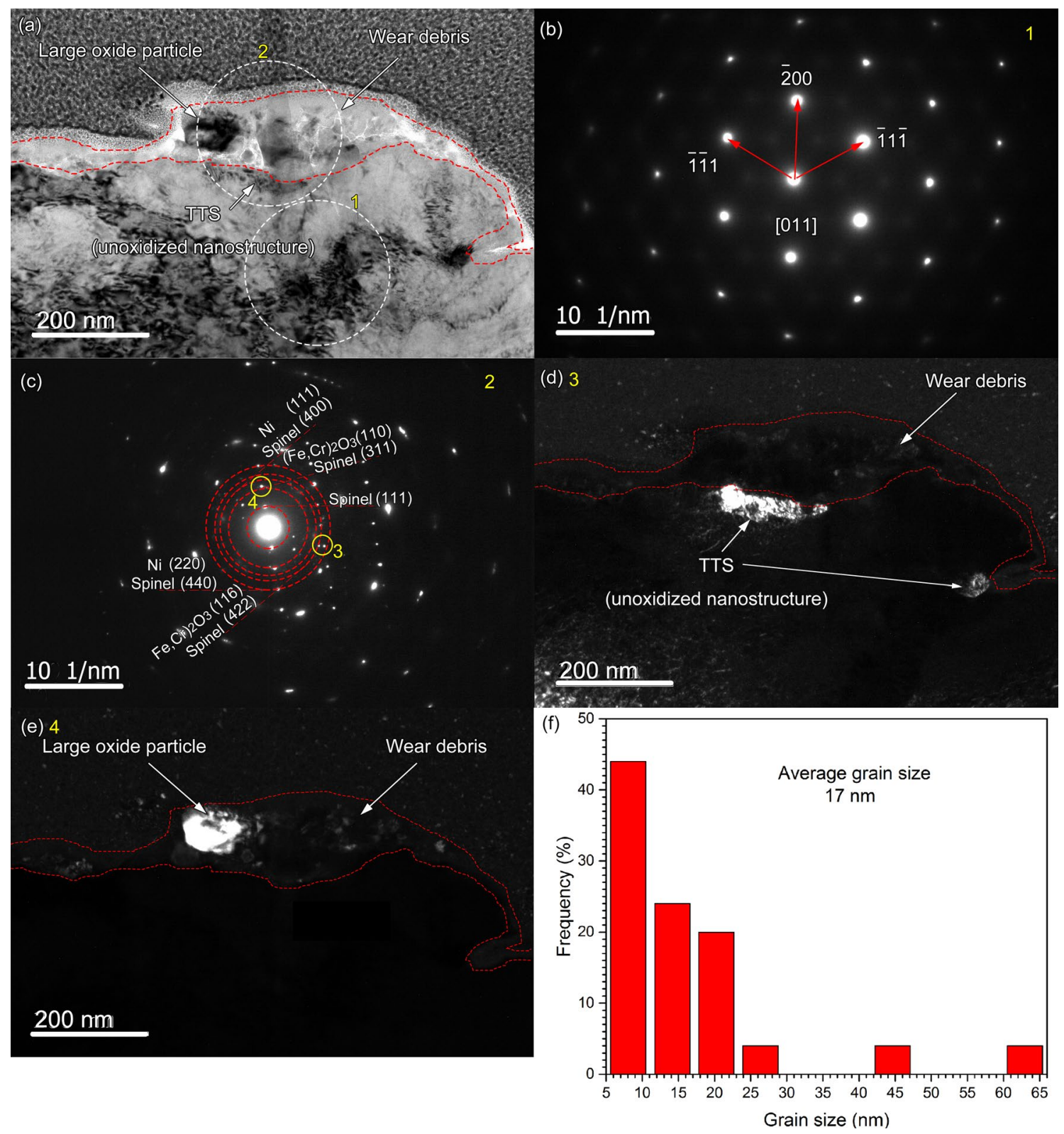

Fig. 9 a BFTEM image obtained from the rectangle 3 marked in Fig. 7c, b, c SAED patterns from locations 1 and 2 in a, respectively, d, e corresponding DFTEM images obtained from different diffraction spots in $\mathbf{c}$, respectively, $\mathbf{f}$ measured distribution of grain size in oxide layer

\section{Discussion}

\subsection{Oxidation in Sticking Region}

In sticking region, the metal-to-metal contact popularly occurred with low extent of oxidation because the oxygen in environment is difficult to enter and react with the contacting materials. Therefore, in many fretting cases, such as in air at room temperature [32] and high temperature [18], and even in high-temperature water [12], the oxygen content in sticking region was low and similar to that on unworn surface, as shown in Fig. 2c. Even so, it is important to note that oxidation can still occur. This is because the real contact condition is the toughing asperities. The real contact area is smaller than the apparent contact area [33]. Therefore, there are some gaps between the contacting bodies in sticking region where a small quantity of high-temperature water can pass through to oxidize the materials, as shown in Figs. $2 \mathrm{c}$ and 3. In the early stage of oxidation of the material exposed to high-temperature water, the elements of $\mathrm{Ni}$ and $\mathrm{Fe}$ selectively dissolved into high-temperature water and the remnant metallic element of $\mathrm{Cr}$ was oxidized to be $\mathrm{Cr}_{2} \mathrm{O}_{3}$ through solid-state reactions $[34,35]$. Another reason for the formation of $\mathrm{Cr}_{2} \mathrm{O}_{3}$ was the higher affinity of $\mathrm{Cr}$ to $\mathrm{O}$ 

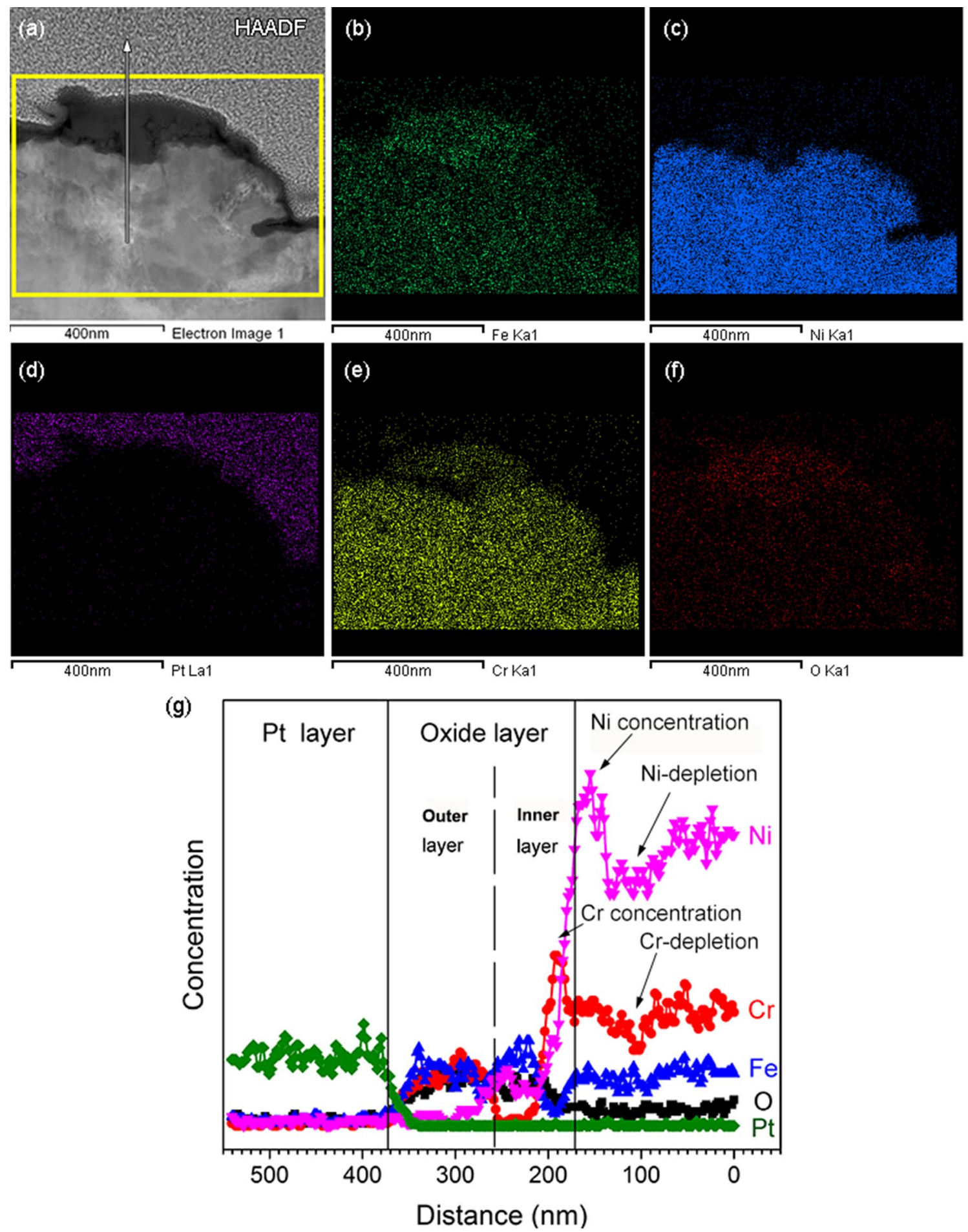

Fig. 10 a STEM-HAADF image of the rectangle 4 marked in Fig. 7d, b-f corresponding EDX elemental mappings of Fe, $\mathrm{Ni}, \mathrm{Pt}, \mathrm{Cr}$ and $\mathrm{O}$ and g EDX profiles for line scan across the wear debris layer. The arrow in a indicates the location and direction of the composition measurements

[34]. Therefore, $\mathrm{Cr}_{2} \mathrm{O}_{3}$ was formed in sticking region. As McIntyre et al. [36] have pointed out that aqueous oxidation results from both solid state and solution transport processes. Due to the higher affinity to $\mathrm{O}, \mathrm{Cr}$ firstly reacts with $\mathrm{O}$ to form $\mathrm{Cr}_{2} \mathrm{O}_{3}$. Meanwhile, a small number of $\mathrm{Ni}$ and $\mathrm{Fe}$ can also react with $\mathrm{O}$ to form single oxide or complex oxide like $(\mathrm{Ni}, \mathrm{Fe})(\mathrm{Fe}, \mathrm{Cr})_{2} \mathrm{O}_{4}[10]$, as shown in Fig. 3. Furthermore, the oxide cluster was formed, which was probably due to the strong adhesion between oxides in sticking region during fretting. 


\subsection{Oxidation in Microslip Region}

According to the previous studies [37-39], wear and corrosion were mutually reinforcing relationship. Although the surface and subsurface deformation would continue to be influenced by wear, the subsequent oxidation process was still controlled by the elemental diffusion and thermodynamic nature of relevant oxides [40]. As mentioned above, the $\mathrm{Cr}_{2} \mathrm{O}_{3}$ oxides were formed initially through solid-state reactions also some $\mathrm{Fe}$-based oxides were formed in the outer layer, as shown in Fig. $10 \mathrm{~g}$. Then $\mathrm{Ni}^{2+}$ and $\mathrm{Fe}^{2+}$ ions could react with $\mathrm{Cr}_{2} \mathrm{O}_{3}$ to generate a small amount of nonstoichiometric spinel oxide $(\mathrm{Ni}, \mathrm{Fe})(\mathrm{Fe}, \mathrm{Cr})_{2} \mathrm{O}_{4}$, as shown in Eq. (1) [34, 41].

$$
\mathrm{Cr}_{2} \mathrm{O}_{3}+\mathrm{Ni}^{2+}+\mathrm{Fe}^{2+}+2 \mathrm{OH}^{-} \rightarrow(\mathrm{Ni}, \mathrm{Fe})(\mathrm{Fe}, \mathrm{Cr})_{2} \mathrm{O}_{4}+\mathrm{H}_{2} \mathrm{O} \text {. }
$$

Therefore, widespread distribution of oxides consisted of $(\mathrm{Ni}, \mathrm{Fe}) \mathrm{Cr}_{2} \mathrm{O}_{4}$, as shown in Fig. 6.

Under high dissolved oxygen concentration (2 ppm in this study), $(\mathrm{Ni}, \mathrm{Fe})(\mathrm{Fe}, \mathrm{Cr})_{2} \mathrm{O}_{4}$ might lose its $\mathrm{Cr}$ as $\mathrm{CrO}_{4}{ }^{2-}$ and Cr-depleted oxide ( $\mathrm{Ni}, \mathrm{Fe}) \mathrm{Fe}_{2} \mathrm{O}_{4}$ formed, as shown in Eq. (2) $[34,41]$.

$$
(\mathrm{Ni}, \mathrm{Fe})(\mathrm{Fe}, \mathrm{Cr})_{2} \mathrm{O}_{4} \rightarrow(\mathrm{Ni}, \mathrm{Fe}) \mathrm{Fe}_{2} \mathrm{O}_{4}+\mathrm{CrO}_{4}^{2-} .
$$

Therefore, Ni-Fe spinel gradually developed on the surface layer by precipitation [34], as shown by inner oxide layer in Fig. 10g. However, outer oxide layer still contained a number of $\mathrm{Cr}$ elements. This was probably due to the effect of fretting that might lead to mechanical mixing between $\mathrm{Cr}_{2} \mathrm{O}_{3}$ and $(\mathrm{Ni}, \mathrm{Fe})(\mathrm{Fe}, \mathrm{Cr})_{2} \mathrm{O}_{4}$. As immersion time increases, some tiny oxide particles gradually develop into large particles by precipitation, as shown in Figs. 4 and 5 .

\subsection{Substructure Microstructure}

During friction and wear process, the formation and development of an ultra-fine-grained (UFG) or even nanocrystalline (NC) directly below the surface are usually the outcome of the response to plastic deformation [21, 42-44]. Under fretting condition, the UFG or NC microstructure is always called tribologically transformed structure (TTS), which is considered as the first step to establish the third-body layer or wear debris layer $[19,20,45]$. Within PSR, TTS was observed in the microslip region because there was relative slip which supported the idea that a thin TTS layer could be formed due to the stress-strain-induced recrystallization $[19,20]$, as shown in Figs. 8a and 9a. The embedded oxides were harder than that of bulk materials, so the movement of oxides resulted in the stress-strain supporting the recrystallization and plowing. Alloy 690TT is a low stacking fault energy (SFE) material. The discontinuous dynamic recrystallization (DDRX) is frequently observed for low SFE materials, where nucleation of new strain-free grains occurs and these grains grow at the expense of regions full of dislocations [46].

\section{Conclusions}

The surface oxidation and subsurface microstructure of Alloy 690TT induced by partial slip fretting corrosion in high-temperature pure water was investigated in detail. The following conclusions can be drawn.

1. $\mathrm{Cr}_{2} \mathrm{O}_{3}$ oxides were formed in sticking region since a small quantity of high-temperature water could pass through the gaps between the asperities to oxidize the materials.

2. Widespread distribution of oxides in microslip region consisted of $(\mathrm{Ni}, \mathrm{Fe}) \mathrm{Cr}_{2} \mathrm{O}_{4}$, which was because $\mathrm{Ni}^{2+}$ and $\mathrm{Fe}^{2+}$ ions could react with $\mathrm{Cr}_{2} \mathrm{O}_{3}$ to generate a small amount of non-stoichiometric spinel oxides.

3. The oxides around micropitting in microslip region consisted of double-layer structure. The outermost layer contained (Fe, $\mathrm{Cr}$ )-rich oxides, which was due to the effect of fretting leading to mechanical mixing between $\mathrm{Cr}_{2} \mathrm{O}_{3}$ and $(\mathrm{Ni}, \mathrm{Fe})(\mathrm{Fe}, \mathrm{Cr})_{2} \mathrm{O}_{4}$. The inner layer consisted of $(\mathrm{Fe}, \mathrm{Ni})$-rich oxides, which was owing to the consumption of $\mathrm{Cr}_{2} \mathrm{O}_{3}$ by the reaction with $\mathrm{Ni}^{2+}$ and $\mathrm{Fe}^{2+}$ ions.

4. The reciprocating motion of oxide particles in microslip region resulted in the stress-strain supporting the recrystallization for the formation of a tribologically transformed structure in subsurface and plowing effect by fretting in surface.

Acknowledgements We thank Xue Liang from Shanghai University for assistance in FIB and TEM experiments. We are grateful for the financial supports of the Beijing Natural Science Foundation (Grant No. 2194081), the Project funded by China Postdoctoral Science Foundation (Grant No. 2018M641187) and the Fundamental Research Funds for the Central Universities (Grant No. FRF-TP-18-047A1).

\section{References}

[1] S.J. Zinkle, G.S. Was, Acta Mater. 61, 735 (2013)

[2] J. Gao, F.R. Wan, G. Cao, K. Sridharan, T.M. Allen, Acta Metall. Sin. Engl. Lett. 29, 774 (2016)

[3] D. Scott, Metall. Rev. 18, 88 (1973)

[4] Z.D. Fan, J.S. Du, Z.B. Zhang, Y.C. Ma, S.Y. Cao, K. Niu, C.X. Liu, Eng. Fail. Anal. 96, 340 (2019)

[5] P.L. Ko, Tribol. Int. 20, 66 (1987)

[6] X.C. Liu, H.L. Ming, Z.M. Zhang, J.Q. Wang, L.C. Tang, H. Qian, Y.C. Xie, E.H. Han, Acta Metall. Sin. Engl. Lett. 32, 1437 (2019) 
[7] X.L. Guo, P. Lai, L. Li, L.C. Tang, L.F. Zhang, Ann. Nucl. Energy 144, $107556(2020)$

[8] L. Xin, Y.H. Lu, T. Shoji, Mater. Charact. 131, 157 (2017)

[9] J.Y. Yun, H.S. Lee, D.H. Hur, W.S. Kang, C.H. Bae, S.J. Kim, Wear 368-369, 344 (2016)

[10] F.H. Stott, Tribol. Int. 31, 61 (1998)

[11] L. Xin, B.B. Yang, J. Li, Y.H. Lu, T. Shoji, Wear 390, 71 (2017)

[12] H.L. Ming, X.C. Liu, Z.M. Zhang, J.Q. Wang, E.H. Han, Tribol. Int. 126, 133 (2018)

[13] X.L. Guo, P. Lai, L.C. Tang, J.M. Wang, L.F. Zhang, Tribol. Int. 116, 155 (2017)

[14] P. Lai, X.C. Gao, L.C. Tang, X.L. Guo, L.F. Zhang, Nucl. Eng. Des. 327, 51 (2018)

[15] L. Xin, B.B. Yang, Z.H. Wang, J. Li, Y.H. Lu, T. Shoji, Wear 368-369, 210 (2016)

[16] L. Xin, X. Liang, Y.M. Han, Y.H. Lu, T. Shoji, Tribol. Int. 134, 93 (2019)

[17] Z.H. Wang, J. Xu, J. Li, L. Xin, Y. Lu, T. Shoji, Y. Takeda, Y. Otsuka, Y. Mutoh, T. Nucl. Mater. 502, 255 (2018)

[18] L. Xin, H.J. Luo, J.L. Han, Y.H. Lu, T. Shoji, Mater. Charact. 132, 284 (2017)

[19] Z.R. Zhou, E. Sauger, J.J. Liu, L. Vincent, Wear 212, 50 (1997)

[20] E. Sauger, L. Ponsonnet, J.M. Martin, L. Vincent, Tribol. Int. 33, $743(2000)$

[21] L. Xin, B.B. Yang, Z.H. Wang, J. Li, Y.H. Lu, T. Shoji, Mater. Des. 104, $152(2016)$

[22] E. Sauger, S. Fouvry, L. Ponsonnet, P. Kapsa, J.M. Martin, L. Vincent, Wear 245, 39 (2000)

[23] J. Kim, K.J. Choi, C.B. Bahn, J.H. Kim, J. Nucl. Mater. 449, 181 (2014)

[24] J.H. Kim, I.S. Hwang, Nucl. Eng. Des. 235, 1029 (2005)

[25] J.E. Maslar, W.S. Hurst, W.J. Bowers, J.H. Hendricks, M.I. Aquino, J. Electrochem. Soc. 147, 2532 (2000)

[26] J.E. Maslar, W.S. Hurst, W.J. Bowers, J.H. Hendricks, M.I. Aquino, I. Levin, Appl. Surf. Sci. 180, 102 (2001)
[27] J.E. Maslar, W.S. Hurst, J.H. Hendricks, M.I. Aquino, W.J.B. Jr, Corrosion 58, 739 (2002)

[28] Z. Wang, S. Saxena, P. Lazor, H. O’Neill, J. Phys. Chem. Solids 64, 425 (2003)

[29] T.T. Xiao, C.L. Yang, Y.G. Lu, F.L. Zeng, J. Mater. Sci. Mater. Electron. 25, 3364 (2014)

[30] T. Miyazawa, S. Uchida, T. Satoh, Y. Morishima, T. Hirose, Y. Satoh, K. Inuma, Y. Wada, H. Hosokawa, N. Usui, J. Nucl. Sci. Technol. 42, 233 (2005)

[31] Y. Matsuda, S. Hinotani, K. Yamanaka, Tetsu-to-Hagane 79, 48 (1992)

[32] L. Xin, Z.H. Wang, J. Li, Y.H. Lu, T. Shoji, Tribol. Trans. 60, 913 (2017)

[33] R.B. Waterhouse (ed.), Fretting Corrosion (Pergamon Press, Oxford, 1972)

[34] W.J. Kuang, X.Q. Wu, E.H. Han, J.C. Rao, Corros. Sci. 53, 3853 (2011)

[35] L. Xin, B.B. Yang, J. Li, Y.H. Lu, T. Shoji, Corros. Sci. 123, 116 (2017)

[36] N.S. Mcintyre, D.G. Zetaruk, D. Owen, Appl. Surf. Sci. 2, 55 (1978)

[37] Y. Zhang, X.Y. Yin, J.Z. Wang, F.Y. Yan, Corros. Sci. 88, 423 (2014)

[38] M. Lgried, T. Liskiewicz, A. Neville, Wear 282, 52 (2012)

[39] Y. Zhang, X.Y. Yin, F.Y. Yan, Mater. Chem. Phys. 379, 273 (2016)

[40] H.L. Du, P.K. Datta, I. Inman, R. Geurts, C. Kübel, Mater. Sci. Eng. A 357, 412 (2003)

[41] Y.J. Kim, Corrosion 56, 389 (2000)

[42] X. Chen, Z. Han, K. Lu, Scr. Mater. 101, 76 (2015)

[43] F. Ren, S.N. Arshad, P. Bellon, R.S. Averback, M. Pouryazdan, H. Hahn, Acta Mater. 72, 148 (2014)

[44] X.C. Liu, H.W. Zhang, K. Lu, Science 342, 337 (2013)

[45] S. Descartes, M. Busquet, Y. Berthier, Wear 271, 1833 (2011)

[46] K. Huang, R.E. Logé, Mater. Des. 111, 548 (2016) 